\title{
Tizanidine (Hydrochloride) Inhibits A549 Lung Cancer Cell Proliferation and Motility Through Regulating Nischarin
}

This article was published in the following Dove Press journal: OncoTargets and Therapy

\section{Liang Zhao \\ Gefei Zhao \\ Qi Xue}

Department of Thoracic Surgery, Cancer Hospital, Chinese Academy of Medical Sciences, Beijing 10002I, People's

Republic of China
Correspondence: Qi Xue

Department of Thoracic Surgery, Cancer Hospital, Chinese Academy of Medical Sciences, Beijing I0002I, People's

Republic of China

Tel +86-I380I204967

Email qixue02@sina.com
Purpose: Tizanidine hydrochloride (TZN) is a centrally acting $\alpha_{2}$-adrenergic agonist. In this study, we aimed to explore the role of TZN on human lung cancer and to elucidate its underlying mechanisms.

Methods: The effect of TZN treatment in A549 cell proliferation, migration, invasion and apoptosis was evaluated by CCK8, transwell and flow cytometer assays. The expression of apoptosis-related proteins and the activation of AKT and Wnt $3 \mathrm{a} / \beta$-catenin pathways were detected by Western blot. From the data of DrugBank, TZN could act as an agonist to target Nischarin in humans. We next investigated the function of Nischarin receptor in lung cancer and its role in the anti-tumor activity of TZN.

Results: The treatment of TZN inhibited the proliferation, migration and invasion of A549 cells, and induced apoptosis. These results were further confirmed by that TZN treatment increased the Bax/Bcl-2 ratio in A549 cells. We also observed that TZN treatment changed the expression and phosphorylation of proteins of AKTand Wnt3a/ $\beta$-catenin signaling pathway members. By bioinformatics analysis, we found that Nischarin was down-regulated in human lung cancer tissues and patients with high Nischarin expression had a better survival. Moreover, Nischarin functioned as a tumor suppressor in the survival and metastasis of A549 cells through the regulation of AKT and Wnt $3 \mathrm{a} / \beta$-catenin pathways. Knockdown of Nischarin promoted the proliferation, invasion, migration of A549 cells and inhibited the apoptosis, which were reversed by the TZN treatment.

Conclusion: Summary, our data revealed that treatment of TZN inhibited the growth of lung cancer cell line A549 and may be used as a novel strategy for lung cancer therapy.

Keywords: Tizanidine, lung cancer, A549, apoptosis, AKT pathway

\section{Introduction}

Lung cancer is the highest morbidity and mortality malignancy in the world, associated with approximately $18 \%$ of cancer deaths. ${ }^{1-3}$ Non-small cell lung cancer (NSCLC) accounts for $85-90 \%$ of all lung cancer cases, with a 5-year survival rate of no more than $15 \% .^{4-6}$ In 2017 , about 160,000 lung cancer deaths occur in the United States. ${ }^{7}$ It is estimated that by 2025 , the number of lung cancer patients in China will reach 1 million, making China the world's largest lung cancer country.

Tizanidine hydrochloride (TZN) is a centrally acting $\alpha 2$-adrenergic agonist that acts as a muscle relaxant for the treatment of muscle spasms, cramping, and tightness caused by medical problems such as spine or central nervous system. ${ }^{8}$ In addition, it has a high affinity for $\alpha 2$-agonist receptors, which reduces the 
nervous reflex and thus has an analgesic effect. Therefore, TZN is also prescribed off label for some symptoms of migraine and fibromyalgia. ${ }^{9}$

Nischarin is initially identified as an $\sim 190 \mathrm{kDa}$ cytosolic protein. It has been reported to be a tumor suppressor gene in human breast and ovarian cancers and plays important roles in tumor cell apoptosis and metastasis. ${ }^{10,11}$ From the data of DrugBank, TZN could act as an agonist to target Nischarin in humans. Therefore, TZN may exert an anti-tumor activity through interaction with Nischarin in human lung cancer.

In this study, we aimed to explore the role of TZN and Nischarin on human lung cancer and to elucidate its underlying mechanisms. Here, we reported that treatment of TZN inhibited A549 cell viability and induced apoptosis through AKT and Wnt3a/ $\beta$-catenin signaling pathways. Moreover, the anti-proliferation activity of TZN was dependent on Nischarin in A549 cells. These data suggest that TZN may be a new agent for lung cancer therapy.

\section{Materials and Methods}

\section{Cell Culture and Treatments}

Human lung cancer cell line A549 was purchased from the cell bank of the Chinese academy of sciences (Shanghai, China). Cells were incubated in DMEM medium containing $10 \%$ FBS, $100 \mathrm{U} / \mathrm{mL}$ Penicillin and $0.1 \mathrm{mg} / \mathrm{mL}$ Streptomycin at $37^{\circ} \mathrm{C}$ with $5 \% \mathrm{CO}_{2}$. TZN $(20 \mu \mathrm{M})$ was applied to cells at $\sim 80 \%$ confluence for $24 \mathrm{hrs}$ and DMSO (1:1000) was used as control. Nischarin siRNA (50nM) was transfected into A549 cells (at $80 \%$ confluence) using Lipo2000 (Invitrogen; USA) in accordance with the manufacturer's instructions. A scrambled siRNA was used as a negative control (NC). The sequences of siRNAs were as follows:

siRNA1: 5'-GCTTCCAACAGGGTCAGAC-3', siRNA2: 5'-CCAACAGGGTCAGACACAG-3', siRNA3: 5'-CCTGATGCCAGCTGTTGCT-3', siNC: 5'-UUCUCCGAACGUGUCACGUTT-3'.

\section{Quantitative Real Time PCR (qRT-PCR) Analysis}

Total RNA was extracted from cells with Trizol reagent (Invitrogen, Carlsbad, CA, USA). cDNA was generated using RNA $(1 \mu \mathrm{g})$ with a PrimeScript RT reagent kit (Tiangen, China). qRT-PCR was conducted with IQTM SYBR Green supermix and Applied Biosystems 7500 Detection system. GAPDH was used as an internal control. The expression levels of target genes were quantified through the $2^{-\Delta \Delta C t}$ method. The primers of genes were as follows:
Nischarin-F: 5'-CTCGGAGCTTGTGGACACTT-3',

Nischarin-R: 5'-CAGGTCATGGAAGTCGCTGT-3',

GAPDH-F: 5'-CTCACCGGATGCACCAATGTT-3',

GAPDH-R: 5'-CGCGTTGCTCACAATGTTCAT-3'.

\section{Western Blot}

Cells were lysed with ice-cold RIPA buffer and the protein concentration was detected by BCA method. About $20 \mu \mathrm{g}$ of protein samples was loaded to each well on $10 \%$ SDSPAGE gel. PVDF membrane was blocked with 5\% non-fat milk for $1 \mathrm{hr}$ at room temperature after protein transferring and incubated with primary antibodies in blocking solution at $4^{\circ} \mathrm{C}$ overnight. After washing with TBST for 5 mins 3 times, the membrane was incubated with secondary antibody in blocking buffer at room temperature for $1 \mathrm{hr}$. After washing, the membrane was applied with an ECL substrate for signal development. QUANTITY ONE software scanned grey value to Tubulin for internal control and calculates the relative expression of the target protein.

\section{CCK8 Assays}

Seeding about 1000 cells to each well of 96-well plate. Cell vitality was detected every $24 \mathrm{hrs}$ by adding $10 \mu \mathrm{L}$ of CCK8 reagent. After incubation at $37^{\circ} \mathrm{C}$ for 90 mins, the OD value of excitation light was detected by using an enzyme standard instrument with $450 \mathrm{~nm}$.

\section{Transwell Assays}

For migration assay, A549 cells maintained for $24 \mathrm{hrs}$ were trypsinized and resuspended in a serum-free culture medium. Add $100 \mu \mathrm{L}$ cell suspension containing $1 \times 10^{4}$ cells to each 24-well chambers and add $600 \mu \mathrm{L}$ medium containing $10 \%$ FBS to the outside of the chamber. $24 \mathrm{hrs}$ after incubation at $37^{\circ} \mathrm{C}$, remove non-migrating cells. Migrated cells were fixed with $4 \%$ paraformaldehyde at room temperature for $15 \mathrm{mins}$ and stained with $0.1 \%$ crystal violet for 5 mins. After washing with $1 \times$ PBS, the filters were cut off and mount on slides. Observe, image and count the invaded cells under the microscope. The invasion experiment was similar to the migration experiment except that the chamber required Matrigel coating.

\section{Apoptosis Analysis}

A549 cells were maintained for $48 \mathrm{hrs}$ and were trypsinized with EDTA free trypsin. After washing with BPS, cells were re-suspended in $1 \mathrm{X}$ binding buffer, and cell intensity was adjusted to $3-5 \times 10^{5}$ cells $/ \mathrm{mL}$. $5 \mu \mathrm{L}$ of AnnexinV-FITC was added to $100 \mu \mathrm{L}$ cell suspension, which was incubated at 
room temperature in dark, and then $10 \mu \mathrm{L}$ of $20 \mu \mathrm{g} / \mathrm{mL}$ PI was added for two more minutes' double staining. Results were analyzed with a flow cytometer (BD FACSC anto II, BD Biosciences, San Jose, CA, USA). The apoptotic rate was calculated by Flowjo software.

\section{Statistical Analysis}

Data represented three independent experiments performed in triplicate. Statistical analysis of the data was performed using SPSS18.0 as means \pm standard deviation (SD) or means \pm standard error of mean (SEM). The student's $t$-test was used to determine the significance of all pairwise comparisons. Differences were considered statistically significant for values of $\mathrm{P}<0.05$.

\section{Results}

\section{TZN Inhibits Proliferation, Invasion and Migration of A549 Cells}

We detected the effect of TZN on lung cancer cell A549. At 24 hrs after treatment, there was no big difference between treat and control groups (Figure 1A). At $48 \mathrm{hrs}$, the proliferation of the TZN-treated group showed a lower OD value of excitation light compared with control cells (Figure 1A). This difference is more significant at $72 \mathrm{hrs}$ (Figure 1A). This result indicated that the treatment of $20 \mu \mathrm{M}$ TZN inhibited the proliferation of A549 cells. Transwell assay was used to determine migration and invasion of A549 cells. We treated cell monolayer with 20 $\mu \mathrm{M}$ TZN for $24 \mathrm{hrs}$. Crystal violet-stained cells on TZN treated
A

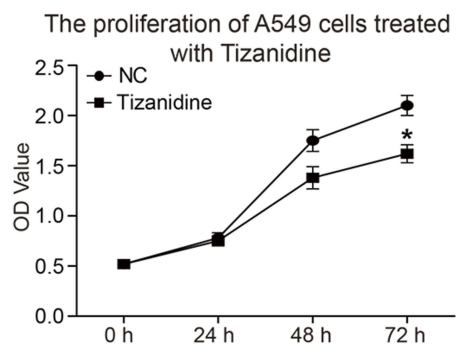

B
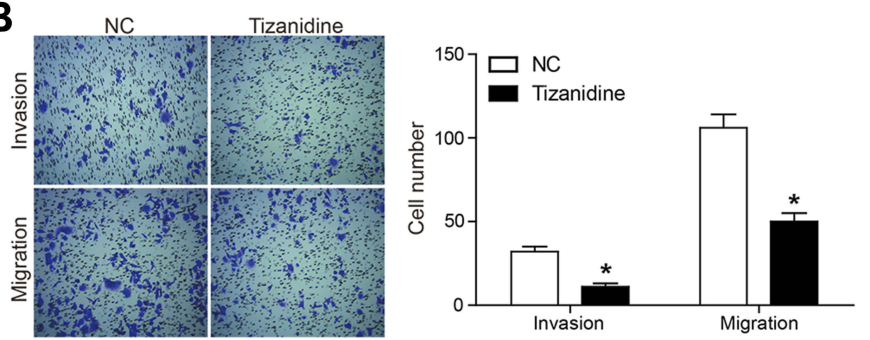
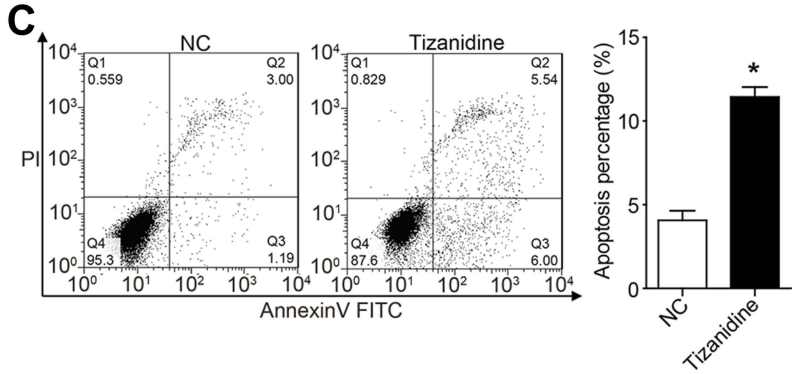

E

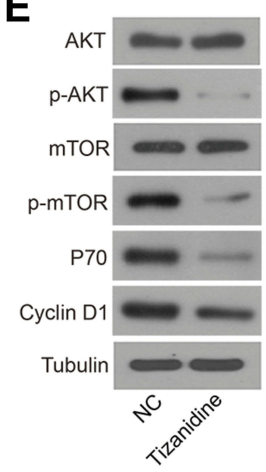

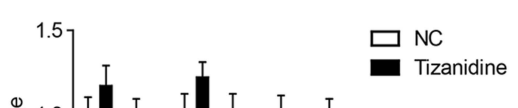

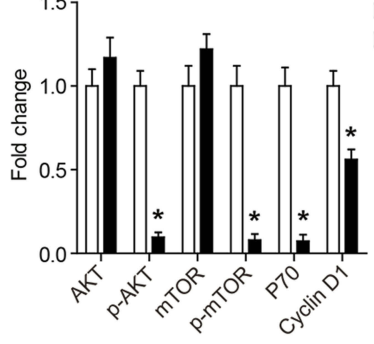

D
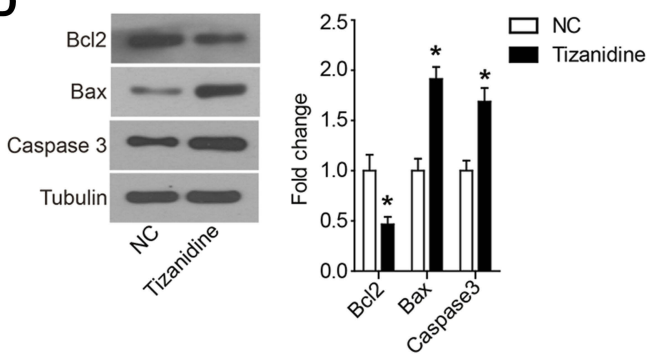

$\mathbf{F}$
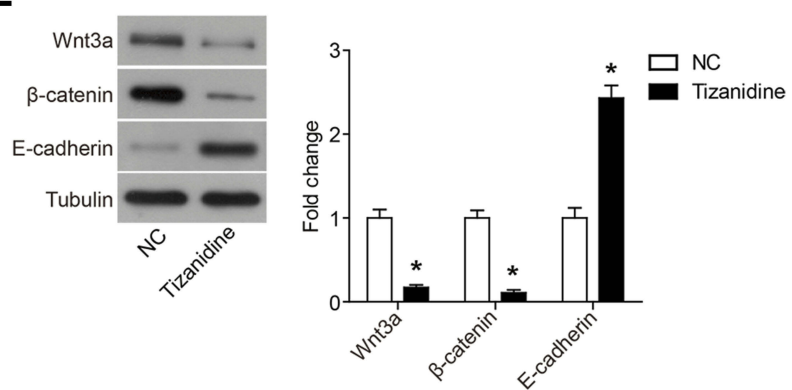

Figure I Tizanidine significantly inhibited proliferation, migration and invasion of A549 cells.

Notes: (A) At 48 and 72 hrs after treatment, the proliferation of A549 cells was significantly decreased than the NC groups. (B) The results of the Transwell experimental results showed that the $A 549$ cell migration capacity was significantly inhibited ( $3 I \pm 4>1 \mid \pm 2$ ) by Tizanidine. The invasion ability was also inhibited (I07 $\pm 5>55 \pm 3$ ). (C) Flow cytometry staining revealed a significant shift in annexin V-FITC-positive cells after Tizanidine treatment in A549 cells. (D) The expression of apoptosis-related protein was analyzed by Western-blot. (E) The expression of PI3K signaling pathway members AKT, p-AKT, mTOR, p-mTOR, P70 and Cyclin DI was analyzed by Western-blot. (F) The expression of Wnt3a/ $\beta$-catenin pathway members Wnt3a, $\beta$-catenin and E-cadherin was analyzed by Western-blot. *P<0.05.

Abbreviations: NC, negative control; FITC, fluorescein isothiocyanate. 
well were much less than control groups (Figure 1B). Transwell experimental results showed that TZN suppressed invasion ability of A549 cells by significant inhibition (31 $\pm 4>11 \pm 2 ; \mathrm{P}<0.05)$ and migration ability under the same inhibition $(107 \pm 5>55 \pm 3 ; \mathrm{P}<0.05)$. These data suggested that the TZN can inhibit the migration and invasion of A549 cells.

\section{TZN Induces Apoptosis in A549 Cells}

The apoptosis of A549 cells treated with TZN was analyzed. TZN treatment significantly increased the apoptosis rate of A549 cells compared with control cells $(11.54 \%>4.19 \%)$ (Figure 1C).

To further confirm the apoptosis induced by TZN, we detected the expression of apoptosis-related proteins with Western blot analysis. Compared with the control group, Bcl-2 expression was decreased, while simultaneous expression of Bax was increased by TZN treatment (Figure 1D). The Bax/Bcl-2 ratio in A549 cells was increased after treated with TZN, which suggested that TZN triggered the mitochondrial apoptotic pathway in A549 cells. For another pro-apoptotic protein, active Caspase-3, TZN treatment significantly increased the expression of Caspase-3 (Figure 1D).

\section{TZN Suppresses the Activation of AKT and Wnt3a/ $\beta$-Catenin Pathways in A549 Cells}

To elucidate the molecular mechanisms involved in TZN affecting the biological function of lung cancer cell, we detected the effect of TZN treatment on PI3K and Wnt3a/ $\beta$ catenin pathways in A549 cells. The results of Western blot showed that in the TZN-treated group, there was no change in the expression of AKT, while in the phosphorylated form p-AKT decreased (Figure 1E). mTOR has the same expression pattern with AKT (Figure 1E). These data suggested that treatment of TZN causes the decrease of the phosphorylated form of AKT and mTOR. The expression of P70 and Cyclin D1 was also decreased by the treatment of TZN (Figure 1E). Here we also found that TZN led to a significant decrease in the levels of Wnt3a and $\beta$-catenin, which suggested that Wnt3a/ $\beta$-catenin pathway was inactivated (Figure $1 F$ ). The expression of E-cadherin was also decreased by the treatment of TZN (Figure 1F).

\section{Nischarin Is Down-Regulated in Human Lung Cancer Tissues and Its}

Overexpression Predicts a Better Prognosis

As TZN functions as an agonist for Nischarin, we further investigated the functions of Nischarin in human lung cancer.
As shown in Figure 2A, compared with normal tissues, Nischarin expression was significantly down-regulated in lung adenocarcinoma (LUAD) and lung squamous cell carcinoma (LUSC) tissues $(\mathrm{P}<0.05)$. Furthermore, we also analyzed the survival correlation of Nischarin in human lung cancer using the Kaplan-Meier plotter (www.kmplot.com) ${ }^{12}$ As shown in Figure 2B, the survival rates of patients with high expression of Nischarin were significantly higher than those with low expression of Nischarin $(\mathrm{P}<0.05)$. Taken together, these results suggested that Nischarin might function as a potential tumor suppressor in human lung cancer.

\section{Down-Regulation of Nischarin Promotes Proliferation, Invasion and Migration and Inhibits Apoptosis of A549 Cells}

We next evaluated the effects of Nischarin knockdown on the proliferation, mobility and apoptosis pf A549 cells. As shown in Figure 2C, siRNA1 and siRNA2 could efficiently down-regulate the mRNA expression of Nischarin in human A549 cells. siRNA1 was used for further function analysis. The Western blot results also validate the inference effects of Nischatin siRNA on protein level (Figure 2D). CCK-8 assay results indicated that NischarinKD significantly promoted the proliferation of A549 cells, compared with the NC group (Figure 2E). Transwell experimental results showed that Nischarin knockdown significantly promoted the invasion and migration ability of A549 cells (Figure 2F, $\mathrm{P}<0.05$ ). Cell apoptosis analysis was also performed. The results indicated that compared with the $\mathrm{NC}$ group, the apoptosis percentage of A549 cells was significantly decreased in the Nischarin knockdown group (Figure 2G, $\mathrm{P}<0.05$ ). Moreover, Nischarin was also involved in the regulation of the mitochondrial apoptotic pathway. As shown in Figure 2H, compared with the NC group, Bcl 2 expression was increased, while simultaneous expression of Bax was decreased by Nischarin knockdown, which suggested that the mitochondrial apoptotic pathway was inactivated. Consistently, the down-stream apoptosis executor active Caspase 3 was also downregulated (Figure 2H).

\section{Down-Regulation of Nischarin Promotes the Activation of AKT and Wnt3a/ $\beta$-Catenin Pathways in A549 Cells}

After function analysis, we also investigated whether Nischarin was involved in the regulation of AKT and Wnt3a/B-catenin pathways. As shown in Figure 3A, 

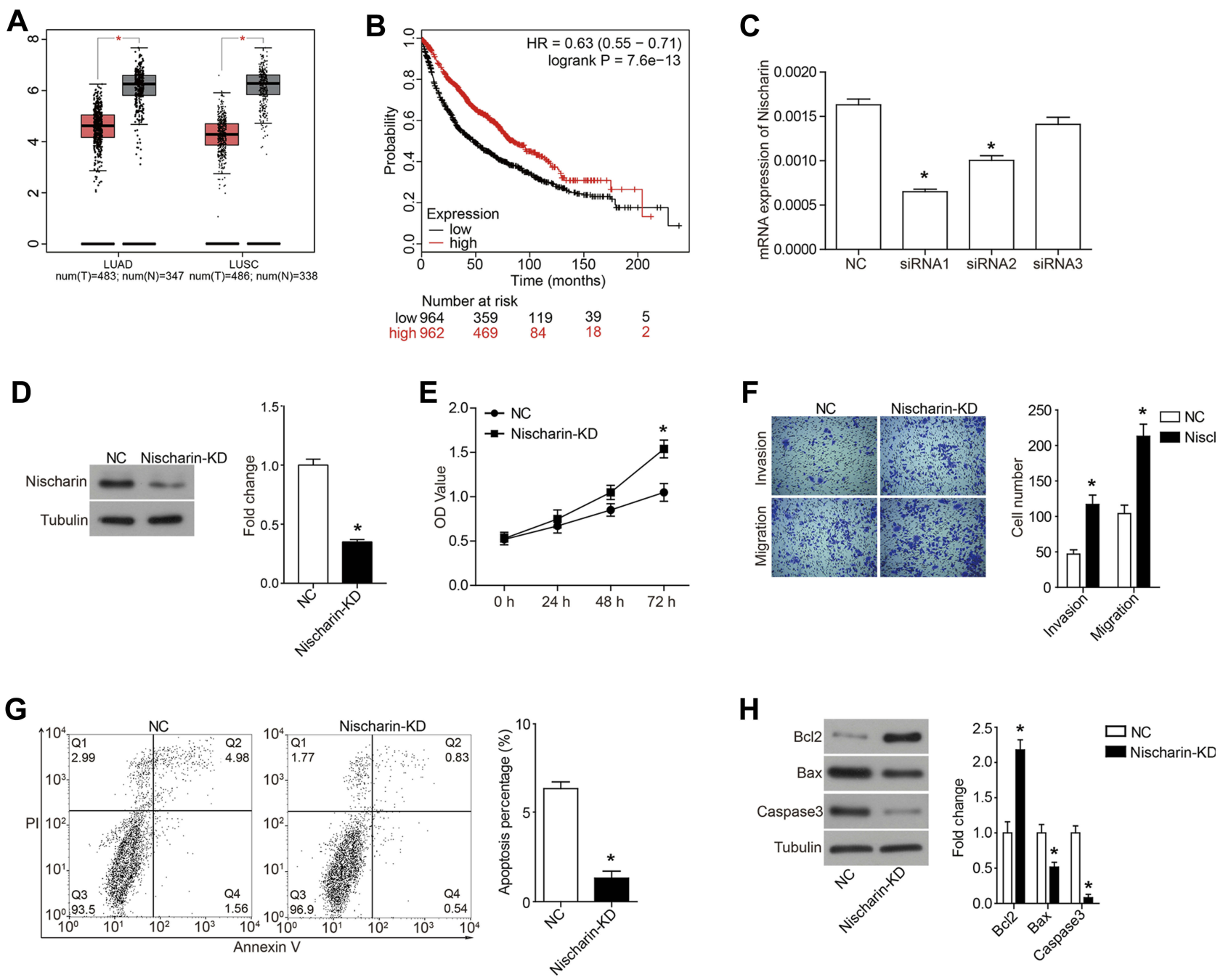

Figure 2 High expression of Nischarin predicts a well prognosis in patients with lung cancer and knockdown of Nischarin promotes proliferation, migration and invasion of A549 cells.

Notes: (A) The red and gray boxes represent human lung cancer and normal tissues, respectively. The y-axis indicates the log2-transformed gene expression level. Left, lung adenocarcinoma (LUAD); Right, lung squamous cell carcinoma (LUSC). The data were obtained from GEPIA (http://gepia.cancer-pku.cn/). (B) Survival percentage of lung patients with high or low Nischarin expression. The data were obtained from the Kaplan-Meier plotter (www.kmplot.com). (C) Three siRNAs targeting Nischarin were synthesized and introduced into A549 cells. The mRNA expression of Nischarin was detected by qRT-PCR. A scrambled siRNA was used as a negative control (NC). (D) The interference effect of Nischarin was validated by Western blot. (E) Nischarin knockdown promoted the proliferation of A549 cells. (F) Cell invasion and invasion were detected using transwell assays. (G) Cell apoptosis was analyzed using flow cytometry. $(\mathbf{H})$ The expression of the apoptosis-related protein was analyzed by Western-blot. $*$ P $<0.05$.

Abbreviations: LUAD, lung adenocarcinoma; LUSC, lung squamous cell carcinoma; NC, negative control.

Nischarin knockdown led to no change in the expression of AKT but increased the level of phosphorylated form p-AKT. mTOR has the same expression pattern with AKT (Figure 3A). Moreover, the expression of P70 and Cyclin D1 was also increased by Nischarin knockdown (Figure $3 \mathrm{~A}$ ). The results of the $\mathrm{Wnt} 3 \mathrm{a} / \beta$-catenin pathway indicated that Nischarin knockdown increased the expression of Wnt3a and $\beta$-catenin and decreased the expression of E-cadherin (Figure 3B). Taken together, these data suggested that Nischarin knockdown induces the activation of AKT and Wnt3a/ $\beta$-catenin pathways in A549 cells.

\section{TZN Treatment Reverses the Affection of Nischarin Down-Regulation}

To comprehensively assess the interaction between TZN and Nischarin on A549 lung cancer cells, we knocked down Nischarin expression and combined it with TZN treatment (Figure 4A). Moreover, TZN could reverse the affection caused by Nischrin-KD, which demonstrated that the antitumor activity of Nischarin was mediated by TZN treatment. As shown in Figure 4B and C, knockdown of Nischarin promoted the proliferation, invasion and migration of A549 cells, which were reversed by the TZN treatment. Furthermore, knockdown of Nischarin inhibited the 


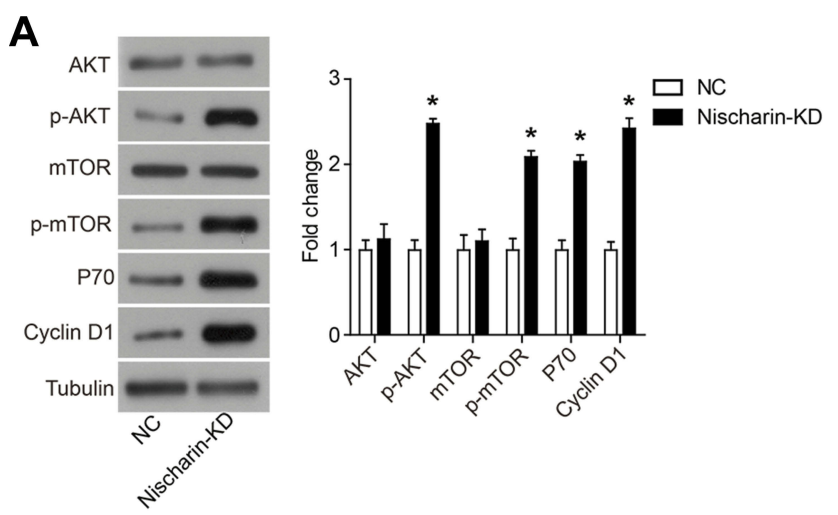

\section{B}

Figure 3 Nischarin knockdown promotes the activation of AKT and Wnt3a/ $\beta$-catenin signaling pathways in A549 cells.

Notes: (A) The expression of PI3K signaling pathway members AKT, p-AKT, mTOR, p-mTOR, P70 and Cyclin DI was analyzed by Western-blot. (B) The expression of $\mathrm{Wnt3a} / \beta$-catenin pathway members $\mathrm{Wnt} 3 \mathrm{a}, \beta$-catenin and $\mathrm{E}$-cadherin was analyzed by Western-blot. $* \mathrm{P}<0.05$.
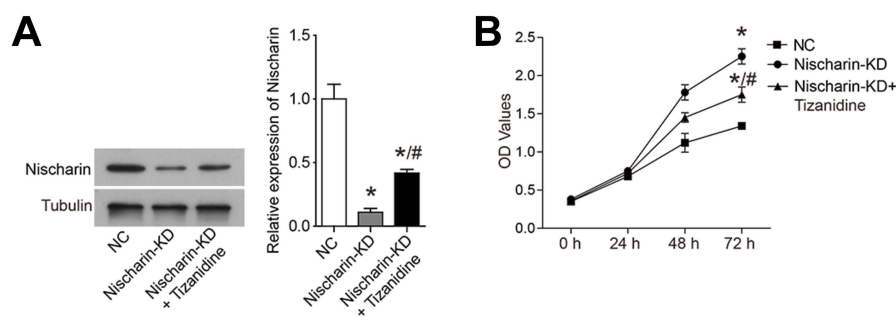

D
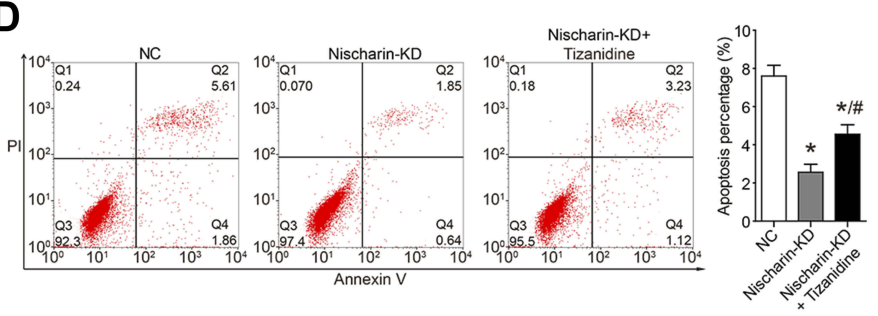

$\mathbf{F}$
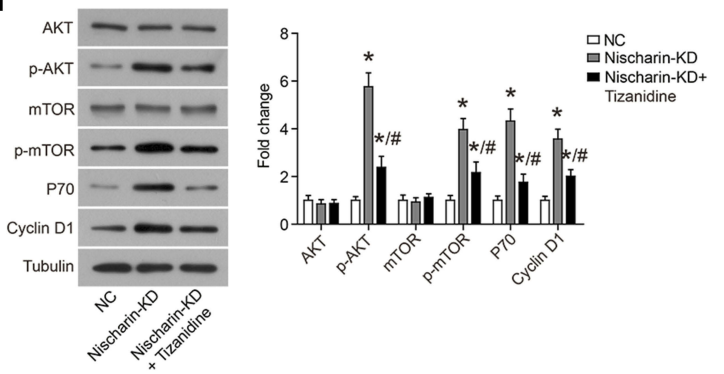
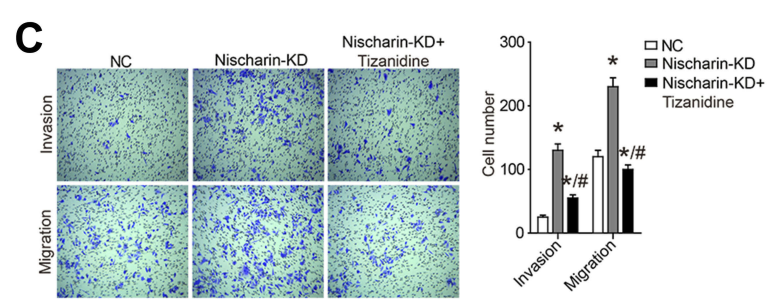

$\mathbf{E}$
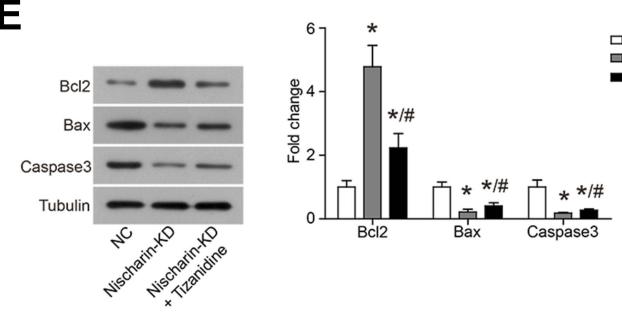

므

Nischarin-KD Tizanidine

G

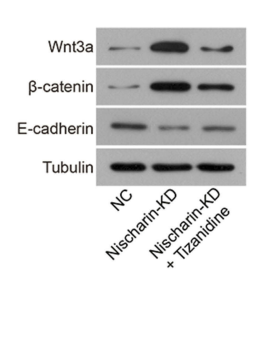

Figure 4 TZN treatment reverses the affection of Nischarin down-regulation.

Notes: (A) The expression of Nischarin was validated by Western blot. (B) Nischarin knockdown promoted the proliferation of A549 cells and reversed the inhibition induced by Tizanidine. (C) Cell invasion and invasion were detected using transwell assays. (D) Cell apoptosis was analyzed using flow cytometry. (E) The expression of apoptosis-related protein was analyzed by Western-blot. (F) The expression of PI3K signaling pathway members AKT, p-AKT, mTOR, P-mTOR, P70 and Cyclin DI was analyzed by Western-blot. (G) The expression of Wnt3a/ $\beta$-catenin pathway members $W n t 3 a, \beta$-catenin and E-cadherin was analyzed by Western-blot. $* P<0.05$, compared to $\mathrm{NC} ;{ }^{\#} \mathrm{P}<0.05$, compared to Nischarin-KD.

Abbreviation: KD, knockdown.

apoptosis of A549 cells, whereas TZN treatment reversed the inhibition on A549 cell apoptosis caused by NischarinKD (Figure 4D and E). Down-regulation of Nischarin promoted the activation of AKT and Wnt3a/ $\beta$-catenin pathways in A549 cells, which were inhibited by the TZN treatment (Figure 4F and G). These data suggest that Nischarin functions as a negative regulator of A549 cell growth and its anti-tumor activity is dependent on TZN treatment. 


\section{Discussion}

For the first time, we reported the role of TZN on human lung cancer cell line A549 and elucidated the underlying mechanisms. Our results showed that treatment of TZN significantly inhibited the proliferation and motility of A549 cells. In addition, TZN induced apoptosis of A549 cells. To further elucidate the mechanism of TZN on inhibiting A549 cells, we studied the effect of TZN treatment on AKT and Wnt3a/ $\beta$-catenin pathway members. We found that TZN treatment decreased the amount of phosphorylated form of AKT and mTOR, which happened at upstream PI3K. Moreover, Wnt3a/ $\beta$-catenin pathway was also inactivated by TZN.

Increasing evidence show that Nischarin functions as a tumor suppressor in human breast cancer. For example, Baranwal et al report that human breast tumor tissues exhibit a significantly lower expression of Nischarin than normal tissues and its overexpression inhibits tumor growth and metastasis of MDA-MB-231 and MCF-7 tumor xenografts. ${ }^{13}$ Chang et al report that expression of Nischarin negatively correlates with estrogen receptor and promotes apoptosis and inhibits migration and invasion in human breast cancer. ${ }^{10}$ However, currently very little is known about the function of Nischarin in human lung cancer. Here we found that Nischarin was downregulated in human lung cancer tissues compared with normal tissues and Nischarin overexpression predicts a good survival of cancer patients. Furthermore, we identified that Nischarin knockdown promoted cell proliferation, migration, invasion and inhibited apoptosis in A549 cells through up-regulation of AKT and Wnt3a/ $\beta$-catenin pathways, which was consistent with the tumor suppressor function of Nischarin reported in other studies. ${ }^{11,13,14}$

Finally, it was reported that TZN treatment reverses the affection of Nischarin knockdown by siRNA transfection. Knockdown of Nischarin promoted the proliferation, invasion, migration of A549 cells and inhibited the apoptosis, which was reversed by the TZN treatment. Downregulation of Nischarin promoted the activation of AKT and Wnt3a/ $\beta$-catenin pathways in A549 cells, which were inhibited by the TZN treatment. These data suggested that the anti-tumor activity of TZN was dependent on its interaction with Nischarin. TZN treatment may up-regulate the expression of Nischarin, or active the Nischarin. This conclusion needs further experimental research.

In conclusion, we first reported that TZN could inhibit the proliferation, migration and invasion of lung cancer cell A549 and induce apoptosis via inhibiting the activation of
AKT and Wnt3a/ $\beta$-catenin pathways. Moreover, we identified that the anti-tumor activity of TZN was dependent on its interaction with Nischarin.

\section{Author Contributions}

All authors contributed to data analysis, drafting and revising the article, gave final approval of the version to be published, and agree to be accountable for all aspects of the work.

\section{Disclosure}

The authors report no conflicts of interest in this work.

\section{References}

1. Torre LA, Siegel RL, Jemal A. Lung cancer statistics. Adv Exp Med Biol. 2016;893:1-19.

2. Parkin DM, Bray F, Ferlay J, Pisani P. Estimating the world cancer burden: globocan 2000. Int $J$ Cancer. 2001;94(2):153-156. doi:10.1002/(ISSN)1097-0215

3. Lagerwaard FJ, Aaronson NK, Gundy CM, Haasbeek CJ, Slotman BJ, Senan S. Patient-reported quality of life after stereotactic ablative radiotherapy for early-stage lung cancer. $J$ Thorac Oncol. 2012;7(7):1148-1154. doi:10.1097/JTO.0b013e318252cfef

4. Molina JR, Yang P, Cassivi SD, Schild SE, Adjei AA. Non-small cell lung cancer: epidemiology, risk factors, treatment, and survivorship. Mayo Clin Proc. 2008;83(5):584-594. doi:10.1016/S0025-6196(11) 60735-0

5. Cetin K, Ettinger DS, Hei YJ, O’Malley CD. Survival by histologic subtype in stage IV nonsmall cell lung cancer based on data from the surveillance, epidemiology and end results program. Clin Epidemiol. 2011;3:139-148. doi:10.2147/CLEP.S17191

6. Gasparri R, Romano R, Sedda G, et al. Diagnostic biomarkers for lung cancer prevention. J Breath Res. 2018;12(2):027111. doi:10.1088/ 1752-7163/aa9386

7. Siegel RL, Miller KD, Jemal A. Cancer statistics, 2017. CA Cancer J Clin. 2017;67(1):7-30. doi:10.3322/caac.21387

8. Zaman M, Hanif M, Shaheryar ZA. Development of tizanidine HCl-meloxicam loaded mucoadhesive buccal films: in-vitro and in-vivo evaluation. PLoS One. 2018;13(3):e0194410. doi:10.1371/ journal.pone. 0194410

9. Kino Y, Tanabe M, Honda M, Ono H. Involvement of supraspinal imidazoline receptors and descending monoaminergic pathways in tizanidine-induced inhibition of rat spinal reflexes. J Pharmacol Sci. 2005;99(1):52-60. doi:10.1254/jphs.FP0050520

10. Chang C, Wei W, Han D, et al. Expression of nischarin negatively correlates with estrogen receptor and alters apoptosis, migration and invasion in human breast cancer. Biochem Biophys Res Commun. 2017;484(3):536-542. doi:10.1016/j.bbrc.2017.01.109

11. Li J, He X, Dong R, Wang Y, Yu J, Qiu H. Frequent loss of NISCH promotes tumor proliferation and invasion in ovarian cancer via inhibiting the FAK signal pathway. Mol Cancer Ther. 2015;14 (5):1202-1212. doi:10.1158/1535-7163.MCT-14-0911

12. Lanczky A, Nagy A, Bottai G, et al. miRpower: a web-tool to validate survival-associated miRNAs utilizing expression data from 2178 breast cancer patients. Breast Cancer Res Treat. 2016;160 (3):439-446. doi:10.1007/s10549-016-4013-7

13. Baranwal S, Wang Y, Rathinam R, et al. Molecular characterization of the tumor-suppressive function of nischarin in breast cancer. $J$ Natl Cancer Inst. 2011;103(20):1513-1528. doi:10.1093/jnci/djr350

14. Maziveyi M, Alahari SK. Breast cancer tumor suppressors: a special emphasis on novel protein nischarin. Cancer Res. 2015;75 (20):4252-4259. doi:10.1158/0008-5472.CAN-15-1395 


\section{Publish your work in this journal}

OncoTargets and Therapy is an international, peer-reviewed, open access journal focusing on the pathological basis of all cancers, potential targets for therapy and treatment protocols employed to improve the management of cancer patients. The journal also focuses on the impact of management programs and new therapeutic agents and protocols on patient perspectives such as quality of life, adherence and satisfaction. The manuscript management system is completely online and includes a very quick and fair peer-review system, which is all easy to use. Visit http://www.dovepress.com/ testimonials.php to read real quotes from published authors. 